\title{
Raman Spectra and Mechanical Properties of Graphene/Polypropylene Nanocomposites
}

\author{
Siti R. Ahmad, Robert J. Young, and Ian A. Kinloch
}

\begin{abstract}
Graphene/Polypropylene nanocomposites were prepared at different filler loading and different average surface diameter 5, 15 and $25 \mu \mathrm{m}$ of graphene nanoplatelets by using Haake Minilab mixer at $1^{\circ} \mathrm{C}$ and rotor speed 50rpm. Besides, Haake MiniJet is used to obtain dumbbell shape specimen. The effect of filler loading and average surface area of filler in PP/GnP composites on Raman spectrum and tensile properties were studied. Raman spectrum of graphene particles indicate three major spectrums such as D, $G$ and $2 D$ band. In addition, PP/GnP composites shows the Raman band shift quite strong by increasing GnP loading. In general, increased of graphene nanoplatelets loading have increased the value of modulus of elasticity, whereas tensile strength, elongation at break of composites reduced.
\end{abstract}

Index Terms-Graphene, polypropylene, Raman spectroscopy.

\section{INTRODUCTION}

Nanocomposites in polymeric materials offer superior mechanical properties at a lower amount of loading rather than microsize filler [1], [2]. However, the properties is depends on proper selection of nanofiller/matrix weight percentage and the homogenous distribution of filler in polymer matrix due to van der Waals's bonding alignment of nanosizes filler in the matrix [3], [4] . Besides, the fabrication cost of nanofiller exhibit higher compared to microfiller.

The incorporation of graphene in polymer composites such as polypropylene receives interest from industries and research laboratories due to improve of mechanical properties and relatively low cost which is widely used in automobile, household appliance and construction industry [4]. In future application of graphene composites material based on graphene filled polymer composites expected to be an ideal material for several applications such as lightweight gasoline tanks, plastic containers, aircraft component (more fuel-efficient), car parts, medical implants, stronger wind turbines and sport equipments [5], [6].

Graphene is a multifunctional material which is considered

Manuscript received March 15, 2014; revised June 23, 2014. This work was supported in part by the School of Materials, The University of Manchester; Majlis Amanah Rakyat (MARA), Malaysia; Universiti Kuala Lumpur-Malaysian Spanish Institute (UniKL-MSI), Malaysia.

S. R. Ahmad is with the School of Materials, University of Manchester, Manchester, M13 9PL, UK (e-mail: sitirohana.ahmad @postgrad.manchester.ac.uk), on leave from the Mechanical Section, Universiti of Kuala Lumpur-Malaysian Spanish Institute, Kulim, Kedah, 09000, Malaysia (e-mail: sitirohana@msi.unikl.edu.my)

R. J. Young and I. Kinloch are with the School of Materials, University of Manchester, Manchester, M13 9PL, UK (e-mail: robert.young @ manchester.ac.uk, Ian.Kinloch@manchester.ac.uk). as better nanofiller compared to nanotubes and other conventional fillers. It improves the mechanical and thermal properties of nanocomposites to a great extent with a very small loading. The mechanism of polymer-graphene interaction is mainly governed by polarity, molecular weight, hydrophobicity, polymer functionalities, graphene functionalities and graphene-solvent interaction [7], [8].

Graphene is a basic stucture of all graphitic form of carbon in single layer atom (SAL) of $\mathrm{sp}^{2}$ hybridized carbon atom which is tightly packed into a two-dimensional (2D) in honeycomb structure [9]. It has low density that related to lightweight material with $2.3 \%$ light absorbed [10]. Some of the amazing properties of graphene are it is the purest form of carbon, large theoretical specific area $\left(2360 \mathrm{~m}^{2} / \mathrm{g}\right)$, high intrinsic mobility $\left(200,000 \mathrm{~cm}^{2} \mathrm{v}^{-1} \mathrm{~s}^{-1}\right)$, extremely high Young's modulus $(\sim 1.0 \mathrm{TPa})$, thermal conductivity $\left(\sim 5000 \mathrm{Wm}^{-1} \mathrm{~K}^{-1}\right)$ and optical transmittance ( 97.7\%) [11].

Polypropylene (PP) is a commodity polymer which offers a combination of outstanding physical, chemical, mechanical, thermal and electrical properties not found in any other thermoplastic [2], [12]. The use of fillers in the preparation of polymeric compositions increases every year as its contribute to the reduction in the final price of the product, improvement in process ability and capability to use for specific applications [12]-[14].

In this paper, the effect of filler loading and surface diameter GnP particles on Raman spectra and tensile properties of Graphene Nanoplatelets (GnP)/Polypropylene (PP) composites were investigated.

\section{SAMPLES PREPARATION}

\section{A. Material}

A commercially polypropylene used was grade 100-CA50 Polypropylene Homopolymer from Ineos Polyolefins Europe (Ineos Olefin and Polymers Europe). The density of this thermoplastic was specified as $0.9 \mathrm{~g} / \mathrm{cm}^{3}$ [15].

Graphene Nanoplatelets $(\mathrm{GnP})$ : Grade $\mathrm{M}$ with average particle diameters of 5,15 or $25 \mu \mathrm{m}$ were supplied by $\mathrm{XG}$ Sciences, Michigan, United States of America. The average thickness of Grade M GnP particles is approximately $6 \mathrm{~nm}$, a typical surface area about $120-150 \mathrm{~m}^{2} / \mathrm{g}$ and $2.2 \mathrm{~g} / \mathrm{cm}^{3}$ of density [16].

\section{B. Mixing and Injection Moulding}

Compounding of the composite was carried out by using Haake Minilab Rheomax CTW5 Mixing machine at temperature of $180^{\circ} \mathrm{C}$ and rotor speed of $50 \mathrm{rpm}$ for 5 minutes per sample. 
Pure PP was prepared using Haake minilab mixing machine. PP was charged into the mixing chamber immediately after the motor started and was allowed to melt for 5 minutes.

For PP/GnP composites, firstly, polypropylene was charged into the mixing chamber immediately after the motor started and was allowed to melt for 3 minutes. GnP was then charged into the mixing chamber and continue the melt mixing for another 2 minutes. The total mixing time was 5 minutes. The total number of the compositions prepared was 10 .

After that, the composite samples were injection moulded in a Haake Minijet Injection Moulding machine to perform Dumbbell Shape (Standard: ISO 527-2-1BA), thickness $1.5 \mathrm{~mm}$ (as opposed $\geq 2 \mathrm{~mm}$ ) of composites. Injection moulding procedures involve cylinder temperature at $200^{\circ} \mathrm{C}$, mould temperature at $40^{\circ} \mathrm{C}$ under 400 bar of pressure for $10 \mathrm{~s}$. All raw materials were prepared and weighed accordingly as indicated in the formulations in Table I.

TABLE I: FORMULATION OF PP/GnP COMPOSITES WITH DIFFERENT FILLER LOADING FOR AVERAGE GnP DIAMETER $5 \mu \mathrm{m}$ IN POLYPROPYLENE

\begin{tabular}{lcccc}
\hline \hline \multicolumn{1}{c}{ Materials } & $\begin{array}{c}\text { Composites (PP/GnP-5) } \\
\text { (wt \%) }\end{array}$ & $\begin{array}{c}100 / 1 \\
(\mathrm{wt} \%)\end{array}$ & $\begin{array}{c}100 / 3 \\
\text { (wt \%) }\end{array}$ & $\begin{array}{c}100 / 5 \\
\text { (wt \%) }\end{array}$ \\
\hline $\begin{array}{l}\text { Polypropylene, PP } \\
\text { (g) }\end{array}$ & 100 & 99.01 & 97.08 & 95.24 \\
$\begin{array}{l}\text { Graphene } \\
\text { Nanoplatelets } \\
(\text { GnP-5) (g)* }\end{array}$ & 0.00 & 0.99 & 2.91 & 4.76 \\
& & & & \\
\end{tabular}

*Note that: The same amount of GnP is used for PP/GnP-15 and PP/GnP-25 composites at three different compositions.

\section{Characterization AND Mechanical Properties}

\section{A. Raman Spectroscopy}

Raman Spectroscopy is used to study the spectrum of pure $\mathrm{PP}$, particles of GnP and PP/GnP composites. Renishaw 1000 Raman Spectrometers with Olympus BH2-UMA microscopes system were used with Renishaw 1000 Raman Spectrometers with Olympus BH2-UMA microscopes system were used with $632 \mathrm{~nm} \mathrm{HeNe}$. A spot size between 1 to $2 \mu \mathrm{m}$ was obtained by the objective lens with x 50 magnification of long working distance (LWD).

The Raman system was calibrated using a silicon sample which shows a sharp peak at $520 \mathrm{~cm}^{-1}$. After the focus point on a silicon sample was obtained, the Renishaw software was setup to perform a scan for a $10 \%$ laser power, 3 accumulation and $15 \mathrm{sec}$ exposure time. Then, the samples were prepared.

Firstly, the small amount of GnP particle was compressed to obtain a thin flat layer of GnP using two glass slides. Next, one of the slides which have slightly uniform flat layer was located on the test section. After that, the same step as calibration of silicon samples was repeated to obtain the spectrum of each sample (GnP-5, 15 and 25).

For PP pure and composites, the flat surface of dumbbell shape was placed on the test section. The data was recorded and analyzed using WIRE 3.3 software.

\section{B. Tensile Test}

Tensile test of composites was carried out according to ASTM D638 using a Universal Testing Machine (UTM), Instron Model 1121 with Series IX software. The test was performed at $25 \pm 3{ }^{\circ} \mathrm{C}$, room temperature. A cross head speed of $5 \mathrm{~mm} / \mathrm{min}$ was used and the gauge length was set at $5 \mathrm{~mm}$.

In addition, the extensometer or extension-meter was used to measure changes in the length of specimens in stress strain measurements. The tensile properties were measured on 5 identical samples (dumbbell shapes) for each composition and the average value was reported. Tensile strength, elongation at break and modulus of elasticity were recorded and calculated.

\section{RESULT AND DisCUSSION}

\section{A. Raman Spectroscopy}

Fig. 1 shows the Raman spectrum for pure polypropylene. A Raman spectrum for polypropylene material indicates several peaks. First positions of several peaks were located between 800 and $1500 \mathrm{~cm}^{-1}$. The others of peaks were observed between 2700 and $3000 \mathrm{~cm}^{-1}$. The similar trend of PP spectrum was observed by Bhattacharyya et al. [17]

A Raman spectrum is used to allow the ratio of ordered crystalline and disordered $\mathrm{sp}^{2}$ carbon in the material. It can be seen clearly 3 typical peaks for $\mathrm{GnP}$ materials called $\mathrm{D}, \mathrm{G}$ and 2D $\left(G^{\prime}\right)$ bands in Fig. 2.

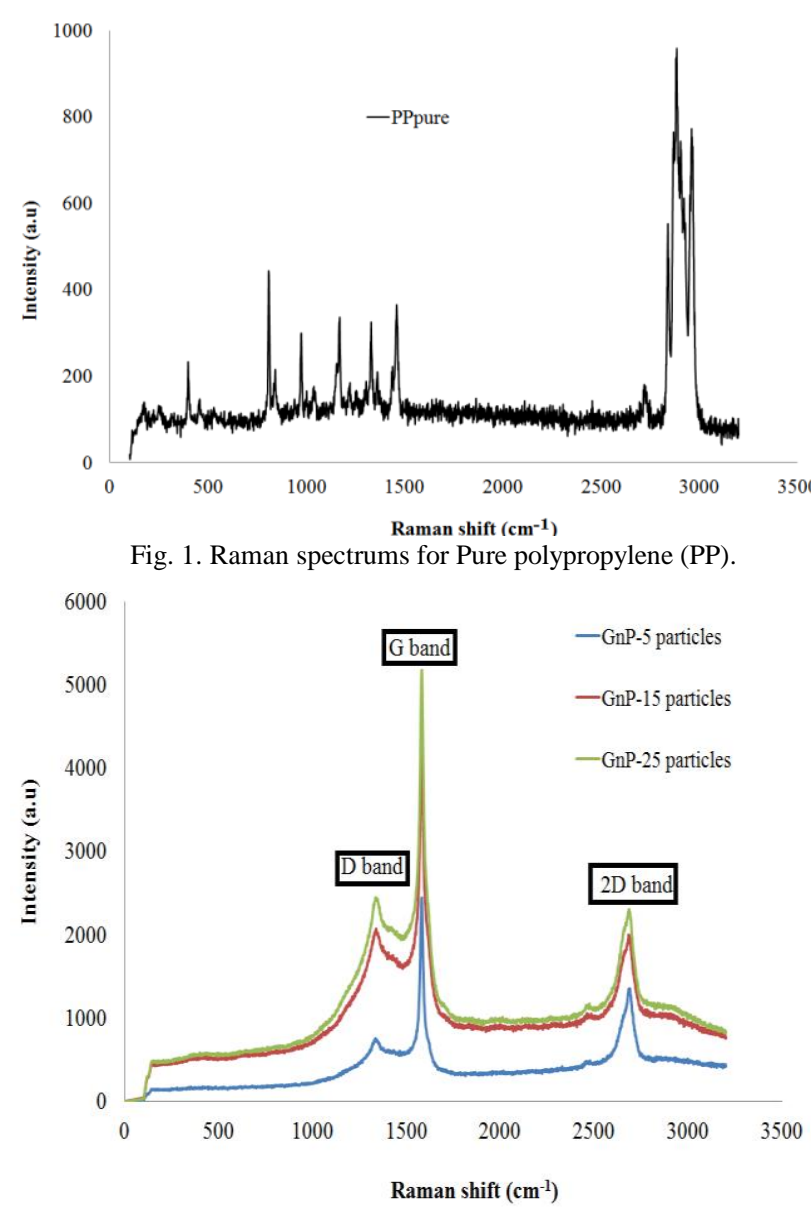

Fig. 2. Raman spectrums for Graphene nanoplatetlets (GnP).

The value of $\mathrm{D}$ band of GnP located at $\sim 1338 \mathrm{~cm}^{-1}$. D band 
also known as defect band which is typically found in difference forms of graphitic carbon. D band is resulted from one phonon lattice vibrational process. $\mathrm{D}$ band is resonant. Normally this band is very weak in graphene and level of defect in sample is about $1300-1400 \mathrm{~cm}^{-1}$ [18]-[20].

The primary peak in graphene and graphite is $\mathrm{G}$ band. This G-band related to the planar congfiguration $\mathrm{sp}^{2}$ bonded carbon that forms graphene. The layer thickness of graphene can be determined using G-band [21].

The $2 \mathrm{D}$ band is used to identify the stacking layers of graphene. $2 \mathrm{D}$ band is resonant like $\mathrm{D}$ band. In this case, the small peak occurred before $2 \mathrm{D}$ band position remains that many layers of graphene are likely graphite which is consisting of an AB-type stacking order [21].

The GnP paticles with $25 \mu \mathrm{m}$ of surface diameter exhibit higher Raman spectrum compared to GnP-15 and GnP-5. It might be due to high surface diameter of $\mathrm{GnP}$ particles strongly interact with the monochromatic light (laser). Some of researcher state that the Raman shift of a mode of dispersion effect of the $\mathrm{D}$ band and the $2 \mathrm{D}$ band are depends on the resonant Raman process [18], [22].

Fig. 3 to Fig. 5 shows the Raman spectrum for PP/GnP-5, 15 and 25 composites at different filler loading. All composites shows D, G and 2D bands of the spectrum located at $\sim 1335, \sim 1585$ and $\sim 2750 \mathrm{~cm}^{-1}$, respectively. It can be seen that the combination of $\mathrm{PP}_{\text {pure }}$ spectrum and $\mathrm{GnP}$ particles spectrum at each composites. The location of $\mathrm{D}$ band is increased by increasing filler loading.

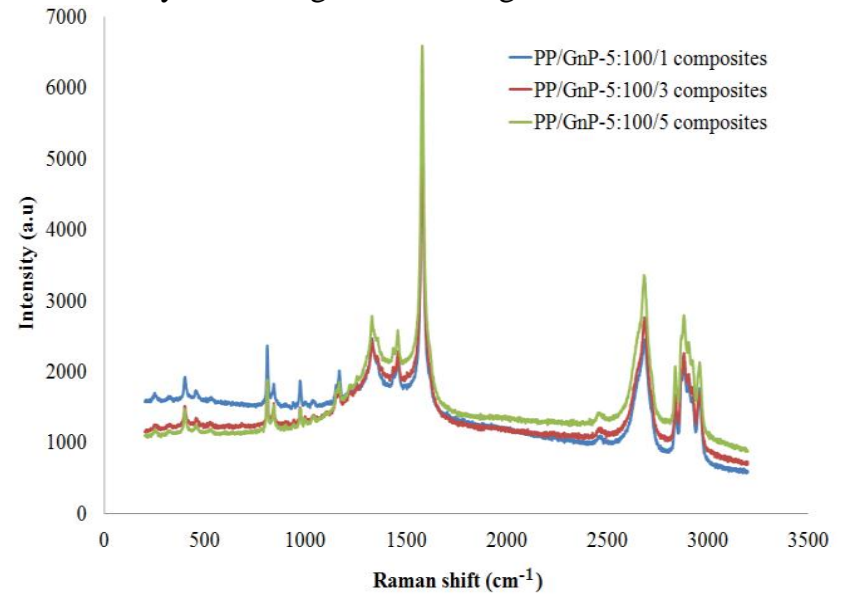

Fig. 3. Raman spectrums for PP/GnP-5 composites at different filler loading.

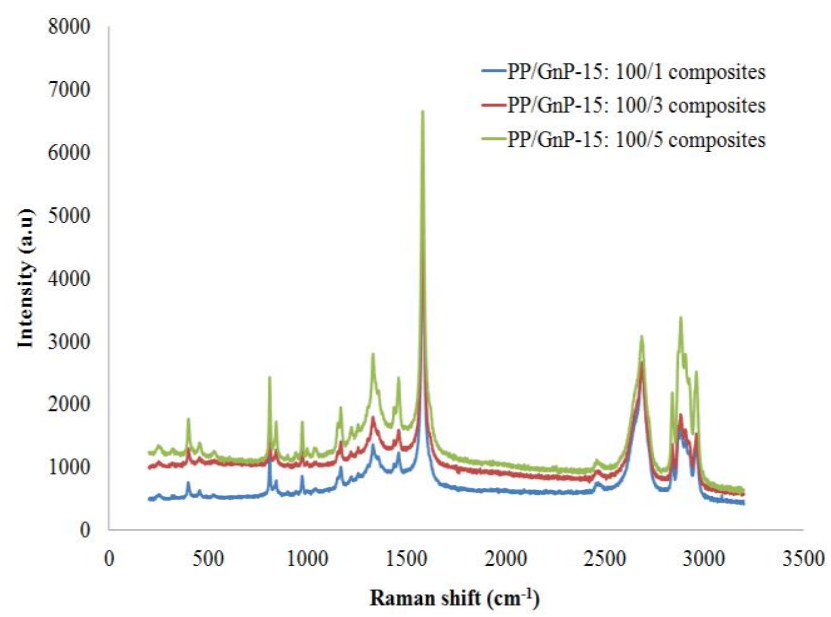

Fig. 4. Raman spectrums for PP/GnP-15 composites at different filler loading.
At 2D band, the location of Raman shift is decreased. At higher filler loading, the effect of PP as a matrix is exhibit lower due to the high modulus of GnP. However, there is slightly small effect at $\mathrm{G}$ band that can be observed using Lorentzian curve fitting.

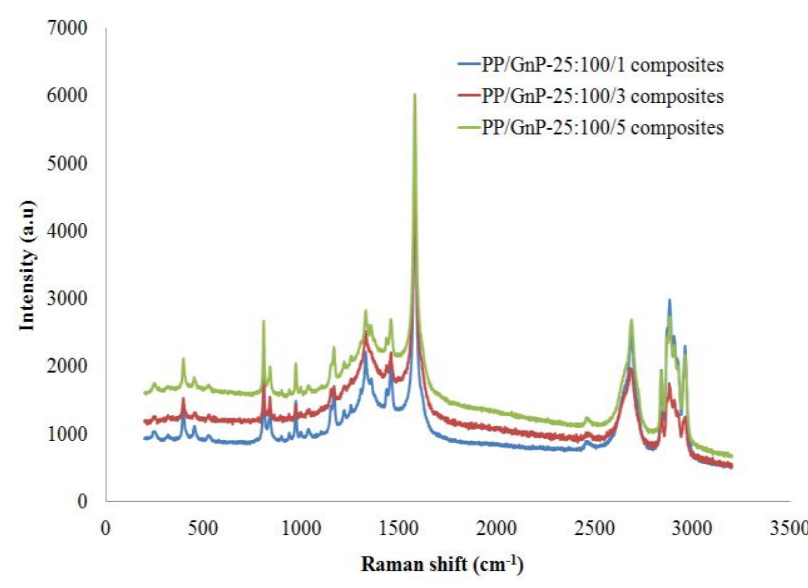

Fig. 5. Raman spectrums for PP/GnP-25 composites at different filler loading.

\section{B. Tensile Testing}

Fig. 6 shows the effect of filler loading on modulus of elasticity of PP/GnP composites. It can be seen that all the composites indicate increasing Young's modulus with increasing filler loading.

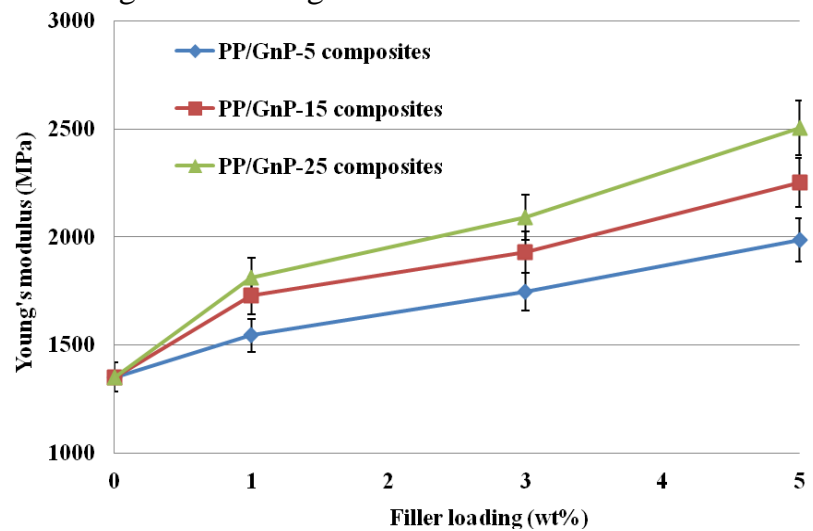

Fig. 6. Young's modulus of PP/GnP composites at different surface area and filler loading.

The addition of 5\% of Graphene nanoplatelets results in an increase of the Young's modulus about $57 \%$ to $67 \%$, as compared with the PP composites without graphene. The increasing of Graphene nanoplatelets $(\mathrm{GnP})$ loading increases the stiffness of the composites. In addition, the small addition of graphene increased the modulus of composites.

The Young's modulus of the composites increases drastically at this low filler contents with strong polymer-filler interfacial action. In general, the modulus increased by inorganic fillers is achieved at the expense of tensile strength, due to the better dispersion of GnP filler in PP matrix, thus improved filler-polymer interfacial stress transfer [2], [23]. At the similar filler loading, PP/GnP-25 composites indicate higher Young's modulus compared to $\mathrm{PP} / \mathrm{GnP}-15$ and $\mathrm{PP} / \mathrm{GnP}-5$ composites due to high aspect ratio and surface area.

The effect of filler loading on tensile strength of PP/GnP composites is shown in Fig. 7. The tensile strength of composites with graphene is lower than the composites 
without graphene nanoplatelets. This might be due to the weak interfacial interaction between the filler and matrix of the composites. Therefore, the presence of filler that acts as foreign materials in the composites that caused the initial crack propagation in the composites itself.

The huge surface area of graphene nanofillers suggested significant improvement in the mechanical properties of the nanocomposites [18]-[25]. Grade M graphene nanoplatetlets particles have an average thickness of approximately 6 nanometers and a typical surface area of $120-150 \mathrm{~m}^{2} / \mathrm{g}$. The average particle diameter is varies about 5, 15 and $25 \mu \mathrm{m}$. Therefore, the PP/GnP-25 composites shows lower tensile properties compared to the PP/GnP-15 and PP/GnP-5 due to the larger surface area.

Fig. 8 and Fig. 9 shows the effect of filler loading on elongation at break of $\mathrm{PP} / \mathrm{GnP}$ composites. The composite without graphene indicates the value of elongation at break is $253.38 \%$. However, the composites with graphene the value of elongation at break are range between 5.5 to $8 \%$. Consequently, the composites with graphene nanopletelets exhibited brittle fracture, whereas the PP composites without graphene revealed plastic behaviour.

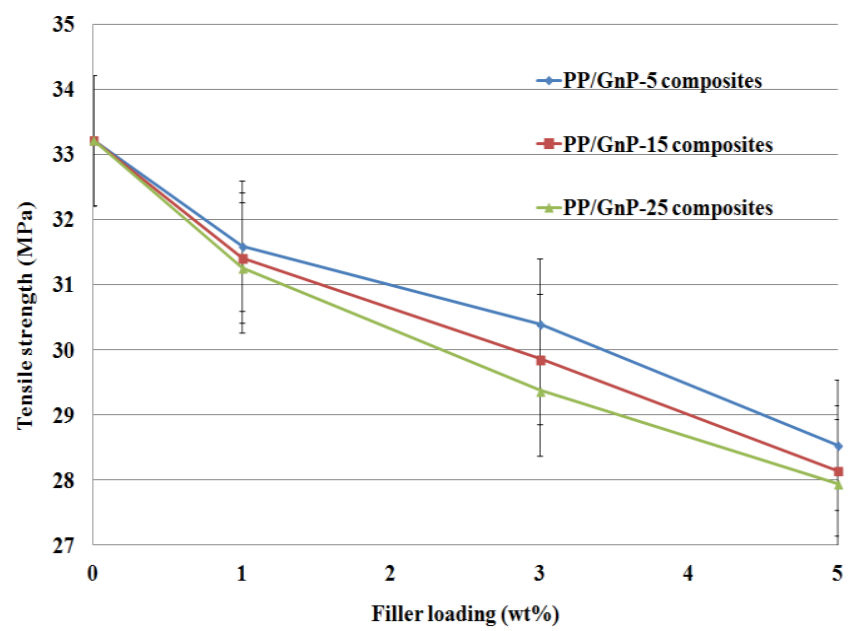

Fig. 7. Tensile strength of $\mathrm{PP} / \mathrm{GnP}$ composites at different average filler

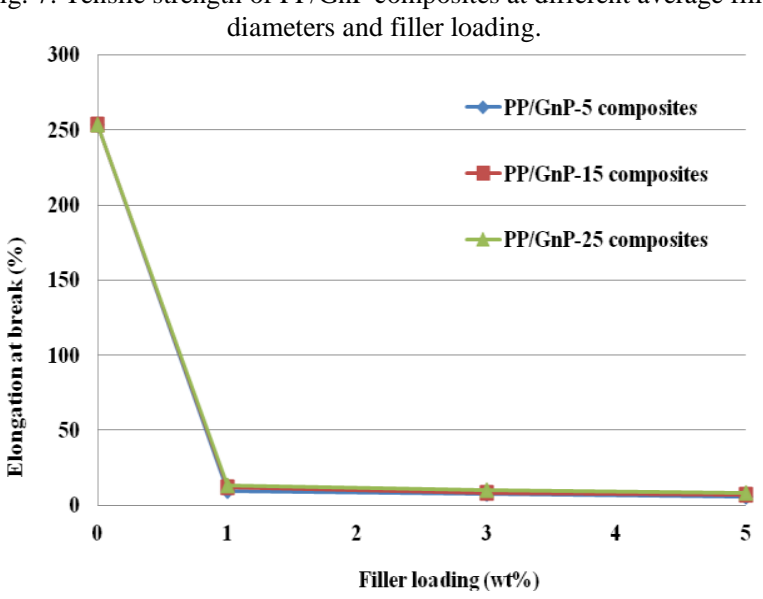

Fig. 8. Elongation at break of $\mathrm{PP} / \mathrm{GnP}$ composites at different surface area and filler loading.

The incorporation of graphene nanoplatelets in the polypropylene matrix resulted in a drastic decrease in the elongation at break of the composites. The reduction of elongation at break with increasing filler loading might be due to the decreased deformability of a rigid interface between the filler and PP matrix [26]. When filler loading is increased, more weak interfacial regions between the filler surface and the PP matrix are formed. These occur because cracks travel more easily through the weaker interfacial regions, the composite fracture at a lower elongation with increasing filler loading.

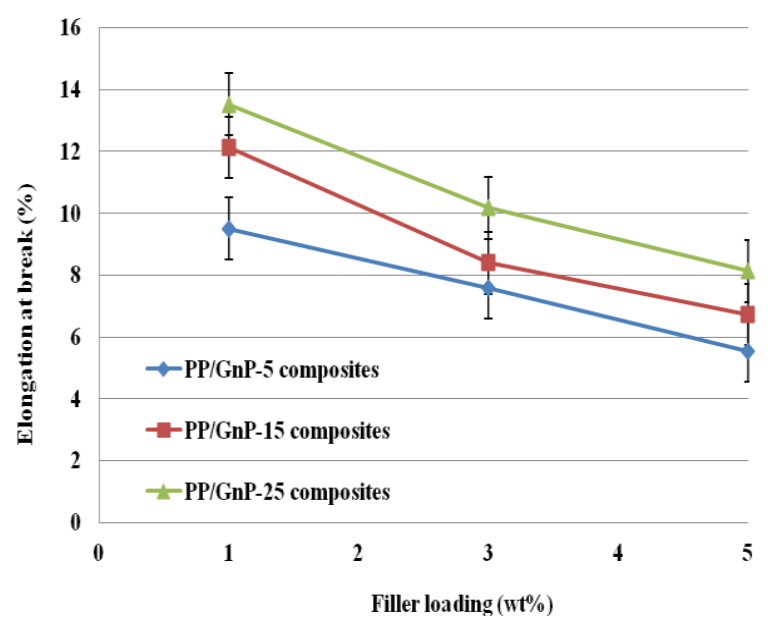

Fig. 9. Elongation at break of $\mathrm{PP} / \mathrm{GnP}$ composites at different surface diameter and 1, $3 \& 5 \mathrm{wt} \%$ filler loading.

At high filler loading it may become difficult to avoid aggregates. Aggregates lead to less ductile behaviour. The dispersion could be a dominating factor in this threshold; when large aggregates are present the voids that are created by debonding are not stable and grow to a size where initial crack occurs [25]. Composites with $25 \mu \mathrm{m}$ of Graphene nanoplatelets diameter seem to be more elastic than composites with 15 and $5 \mu \mathrm{m}$ diameter composites. This related to the lowest value of tensile strength of composites with $25 \mu \mathrm{m} \mathrm{GnP}$ than others.

\section{CONCLUSION}

In conclusion, the Raman spectrum of pure polypropylene (PP), gaphene nanoplatelets (GnP) particles and PP/GNP composites at different filler loading were obtained. Raman spectroscopy analysis indicates three main peaks of GnP such as the D, G and 2D bands. The strongest Raman spectrum of $\mathrm{GnP}$ were occurred at the highest graphene loading (5wt\%). The presence of GnP into PP matrix has resulted in the improvement in the Young's modulus but the tensile strength and elongation at break decreased with increasing filler loading. The excellent performance of Young's modulus was attributed to the better filler-matrix adhesion and the effect of improved in crystallinity.

\section{ACKNOWLEDGMENT}

S. R. Ahmad thanks to Malaysian Government, Majlis Amanah Rakyat (MARA) and Universiti Kuala Lumpur Malaysian Spanish Institute (UniKL MSI) for their financial support during her PhD. A bunch of thanks goes to School of Materials, The University of Manchester for providing her space laboratories with excellent facilities.

\section{REFERENCES}

[1] V. Vladimirov, C. Betchev, A. Vassiliou, G. Papageorgiou, and D. Bikiaris, "Dynamic mechanical and morphological studies of isotactic 
polypropylene/fumed silica nanocomposites with enhanced gas barrier properties," Comp. Sci. \& Tech., vol. 66, no. 15, pp. 2935-2944, 2006.

[2] H. Hanim, R. Zarina, M. A. Fuad, Z. A. M. Ishak, and A. Hassan, "The effect of calcium carbonate nanofiller on the mechanical properties and crystallizing behavior of polypropylene," Malaysian Polym. J., vol. 3, pp. 38-49, 2008.

[3] F. Mirjalili, L. Chuah, and E. Salahi, "Mechanical and Morphological Properties of Polypropylene/Nano $\alpha-\mathrm{Al}_{2} \mathrm{O}_{3}$ Composites," The Scientific World J, pp.1-12, 2014

[4] L. Huang, R. Zhan, and Y. Lu, "Mechanical properties and crystallization behavior of polypropylene/nano- $\mathrm{SiO}_{2}$ composites," $J$. Reinf. Plas. \& Comp., vol. 25, no. 9, pp.1001-1012, 2006.

[5] M. Fang, K. Wang, H. Lu, Y. Yang, and S. Nutt. "Covalent polymer functionalization of graphene nanosheets and mechanical properties of composites." J. Mater Chem., vol. 19, no. 38, pp. 7098-7105, 2009.

[6] S. Stankovich, D. A. Dikin, G. H. Dommett, K. M. Kohlhaas, E. J. Zimney, E. A. Stach, R. D. Piner, S. T. Nquen, and R. S. Ruoff, "Graphene-based composite materials," Nature, vol. 442, no. 7100, pp 282-286, 2006

[7] T. Kuilla, S. Bhadra, D. Yao, N. H. Kim, S. Bose, and J. H. Lee, "Recent advances in graphene based polymer composites," Progress in Polym. Sci., vol. 35, pp. 1350-1375, 2010.

[8] T. Ramanathan, A. A. Abdala, S. Stankovich et al., "Functionalized graphene sheets for polymer nanocomposites," Nature Nanotechnology, vol. 3, no. 6, pp. 327-331, 2008.

[9] A. K. Geim and K. S. Novoselov, "The rise of graphene," Nature materials, vol. 6, no. 3, pp. 183-191, 2007.

[10] R. J. Young, I. A. Kinloch, L. Gong, and K. S. Novoselov, "The mechanics of graphene nanocomposites: A review," Comp. Sci. \& Tech., vol. 72, pp. 1459-1476, 2012

[11] J. Denault and B. Labrecque, "Technology Group on Polymer Nanocomposites," PNC-Tech. Industrial Materials Institute, Nationa Research Council Canada, 75 de Mortagne Blvd. Boucherville, Québec, J4B 6Y4, 2004

[12] K. Kalaitzidou, H. Fukushima, and L. T. Drzal, "Multifuctional polypropylene composites produced by incorporation of exfoliated graphite nanoplatelets," Carbon, vol. 45, pp. 1446-1452, 2007.

[13] T. Taniike, M. Toyonaga, and M. Terano, "Polypropylene-Grafted Nanoparticles as a Promising Strategy for Boosting Physical Properties of Polypropylene-Based Nanocomposites," Polym., vol. 55, no. 4, pp.1012-1019, 2014.

[14] K. Prashantha, J. Soulestin, M. F. Lacrampe, P. Krawczak, G. Dupin, and M. Claes, "Masterbatch-based multi-walled carbon nanotube filled polypropylene nanocomposites: Assessment of rheological and mechanical properties," Comp. Sci. \& Techn., vol. 69, no. 11, pp. 1756-1763, 2009.

[15] Product Technical Information, Polypropylene-Homopolymer 100-CA50, INEOS Olefins \& Polymers Europe. (2008). [Online]. Available: http://www.ineos.com

[16] Technical Data Sheet. $x G n P ®$ Graphene Nanoplatelets - Grade M, XG Sciences, Inc. (2012). [Online]. Available: http://www.xgsciences.com

[17] A. R. Bhattacharyya, T. V. Sreekumar, T. Liu, S. Kumar, L. M. Ericson, R. H. Hauge, and R. E. Smalley, "Crystallization and orientation studies in polypropylene/single wall carbon nanotube composite," Polym., vol. 44, no. 8, pp. 2373-2377, 2003.

[18] C. Casiraghi, A. Hartschuh, H. Qian, S. Piscanec, C. Georgi, A. Fasoli, K. S. Novoselov, D. M. Basko, and A. C. Ferrari, "Raman spectroscopy of graphene edges," Nano letters, vol. 9, no. 4, pp. 1433-1441, 2009.

[19] D. Wagner and R. Vaia, Nanocomposites: Issues at the Interface, Materials Today, November, 2004.

[20] P. Song, Z. Cao, Y. Cai, L. Zhao, Z. Fang, and S. Fu, "Fabrication of exfoliated graphene-based polypropylene nanocomposites with enhanced mechanical and thermal properties," Polym, vol. 52, no. 18, pp. 4001-4010, 2011

[21] J. A. Robinson, M. Wetherington, J. L. Tedesco et al., "Correlating Raman spectral signatures with carrier mobility in epitaxial graphene: a guide to achieving high mobility on the wafer scale," Nano letters, vol. 9, no. 8, pp. 2873-2876. 2009

[22] J. Kastner, T. Pichler, H. Kuzmany, S. Curran, W. Blau, D. N. Weldon, M. Delamesiere, S. Draper, and H. Zandbergen, "Resonance Raman and infrared spectroscopy of carbon nanotubes," Chemical physics letters, vol. 221, no. 1, pp. 53-58, 1994.

[23] M. El Achaby, F. E. Arrakhiz, S. Vaudreuil, A. El Kacem Qaiss, M. Bousmina, and O. Fassi-Fehri, "Mechanical, thermal, and rheological properties of graphene based polypropylene nanocomposites prepared by melt mixing," Polym. Comp., vol. 33, no. 5, pp. 733-744, 2012.
[24] E. V. Kuvardina, L. A. Novokshonova, S. M. Lomakin, S. A. Timan, and I. A. Tchmutin, "Effect of the graphite nanoplatelet size on the mechanical, thermal, and electrical properties of polypropylene/exfoliated graphite nanocomposites," J. Appl. Polym. Sci., vol. 128, no. 3, pp. 1417-1424, 2012

[25] M. El Achaby and A. Qaiss, "Processing and properties of polyethylene reinforced by graphene nanosheets and carbon nanotubes," Materials \& Design, vol. 44, pp. 81-89, 2012.

[26] J. R. Potts, D. R. Dreyer, C. W. Bielawski, and R. S. Ruoff, "Graphene-based polymer nanocomposites," Polym., vol. 52, no. 1, pp. 5-25, 2011.

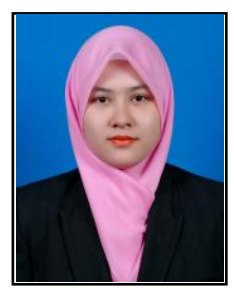

Siti Rohana Ahmad is a PhD student in the School of Materials, University of Manchester, UK.

Ms. Ahmad was born in Alor Setar, Kedah, Malaysia on 20 November 1981. The author hold diploma in mechanical engineering (aerospace) during 2000-2003 and B. Eng. in mechanical engineering during 2003-2006 from Universiti Teknologi MARA, Shah Alam, Selangor, Malaysia She did her MSc. degree in materials engineering (polymer composites) at Universiti Malaysia, Perlis during 2007-2008. At present, she is doing her $\mathrm{PhD}$ in polymer science and engineering (graphene nanocomposites) at The University of Manchester, Manchester, United Kingdom (2012-2016).

She is a lecturer at Universiti Kuala Lumpur Malaysian Spanish Institute, Kulim, Kedah, Malaysia since 2008 until present (on study leave). She taught materials, mechanical and automotive engineering related subjects for both diploma and bachelor degree students in UniKL MSI. She was a research and development coordinator for 2 years (2010-2011) in UniKL MSI.

Currently, she spends her interest on research that related to nanocomposites, polymer composites, Raman spectroscopy, mechanical testing and thermal properties.

Ms. Ahmad becomes a member of Malaysia Society for Engineering and Technology (mSET) and Board of Engineers Malaysia (BEM), Malaysia. She received the outstanding staff in Mechanical section of UniKL MSI awards for year 2010

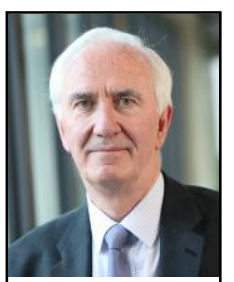

Robert J. Young is a professor of polymer science and technology in the School of Materials, University of Manchester, UK

Professor Young studied natural sciences at the University of Cambridge and gained his PhD in 1973. After working at Queen Mary College in London he became a professor of polymer science and Technology in Manchester in 1986. From 1992 to 1997 he was the royal society wolfson research professor of Material Science. Between 2004 and 2009, he was the head of the School of Materials in the newly-formed University of Manchester. He was elected to the Royal Academy of Engineering in 2006 and to the Royal Society in 2013.

Professor Young's main research interest is the relationships between structure and properties in polymers and composites. He has published over 300 papers and a number of books. He is listed in the ISI HighlyCited.com for his publications in Materials Science.

He has delivered courses in polymer science and technology at both the undergraduate and postgraduate levels and lectured extensively at international conferences. His research interests have extended recently into the field nanotechnology, working in particular upon polymers containing carbon nanotubes or graphene.

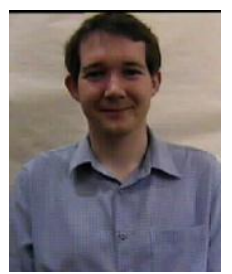

Ian A. Kinloch is a professor of materials science in the School of Materials, University of Manchester, UK.

Professor Kinloch holds an EPSRC Challenging Engineering Fellowship and has previously held an EPSRC/RAEng Research Fellowship. He moved to Manchester in 2006, having previously worked as a PDRA and studied for his $\mathrm{PhD}$ in materials science at the University of Cambridge and getting his BSc. (Hons) in physics at the University of Durham.

He has delivered courses in advanced fuctional materials, nanoscience, and nanotechnology subjects at both undergraduate and postgraduate levels. Professor Kinloch research focus on polymeric and carbon (graphene and nanotubes) and related nanomaterials. The research takes the science from the controlled growth of the nanomaterials through to their processing and applications. His research on applications is based on polymer-nanocarbon composites, electrodes and the bio-nano interface. 